\title{
Concomitant Left Atrial Myxoma and Patent Foramen Ovale: Is It an Evolutional Synergy for a Cerebrovascular Event?
}

\author{
Glenmore Lasam, ${ }^{\mathrm{a}}$, Roberto Ramirez ${ }^{\mathrm{a}}$
}

\begin{abstract}
We report a case of a 48-year-old female who presented initially with an abrupt onset of left facial and hand numbness after her routine yoga with no associated syncope, palpitation, chest pain or dyspnea. She consulted her primary care physician and recommended hospital care for possible stroke. On the day of admission, she complained of left facial and hand hemiparesthesia. Cranial imaging and angiography were unremarkable but echocardiography and cardiac computed tomography revealed left atrial mass. She underwent resection of the left atrial mass with an incidental finding of patent foramen ovale intraoperatively. The left atrial mass was confirmed to be an atrial myxoma. Patient's neurologic complaints resolved towards the end of her hospital course. She was discharged stable with no recurrence of neurologic symptoms on health maintenance evaluation.
\end{abstract}

Keywords: Left atrial myxoma; Patent foramen ovale; Cerebrovascular event; Cardioembolic stroke; Cryptogenic stroke; Paradoxical embolism

\section{Introduction}

Concomitant left atrial myxoma and patent foramen ovale (PFO) is a rare occurrence that presumably predisposes a patient to the evolution of a cerebrovascular event. This would entail an immediate intervention to abate the progression of symptoms and to prevent deleterious complications associated with this risk factor for a stroke.

\section{Case Report}

A 48-year-old female with no known medical illnesses nor previous surgeries, non-contributory family history, and un-

\footnotetext{
Manuscript accepted for publication February 06, 2017

aDepartment of Medicine, Atlantic Health System-Overlook Medical Center, Summit, NJ 07901, USA

${ }^{b}$ Corresponding Author: Glenmore Lasam, Department of Medicine, Overlook Medical Center, 99 Beauvoir Avenue, Summit, NJ 07901, USA.

Email: glenmore_md@yahoo.com
}

doi: https://doi.org/10.14740/cr522w remarkable social profile presented to the hospital because of an acute onset of left facial and hand numbness. She initially began having symptoms 4 days prior in the midst of her yoga class when she developed mild numbness in her face and entire left hand which she initially thought was a pinched nerve. She subsequently aborted her class and took a nap and woke up still with numbness in her left hand. Her symptoms persisted for 3 days. She consulted her primary care physician in which a magnetic resonance imaging was done which reportedly demonstrated an acute stroke. She denied any headache, dizziness, chest pain, palpitations, focal weakness, dysarthria, or dysphagia during this time.

She was hemodynamically stable and not in distress. No appreciable carotid bruit, irregular heart rhythm or cardiac murmurs were found. Neurologic examination revealed normal mentation and orientation, intact cranial nerves, preserved motor strength and tone symmetrically with no drift, and normal cerebellar function but has decreased sensation around $15 \%$ on the left palmar region to light touch and pin prick. Hemogram, comprehensive metabolic panel, lipid panel, and glycosylated hemoglobin were within normal. Electrocardiogram demonstrated sinus rhythm without an ectopy. Chest radiograph showed no acute pulmonary disease. Transthoracic echocardiogram revealed a mass in the left atrium measuring $3.7 \times 2 \mathrm{~cm}$ that appears adherent to the interatrial septum but prolapses into mitral valve inflow without evidence of obstruction (Fig. 1). The left atrial mass did not appear to have a have uniform echodensity, suggesting the possibility of a superimposed thrombus. A bubble study was done which showed no evidence of right-to-left shunting. Cranial computed tomography did not show any focal intracranial lesion, mass, hemorrhage or hydrocephalus. Magnetic resonance angiography of the brain revealed no hemodynamically significant stenosis and aneurysm in the major intracranial and neck vasculature. Carotid duplex scan showed no evidence of hemodynamically significant stenosis in the left carotid system. Cardiac computed tomography showed filling defect in the left atrium measuring $3 \mathrm{~cm}$ which could represent a thrombus (Fig. 2).

The left atrial mass was suspected as the etiology of her acute cerebrovascular event. Patient underwent cardiac surgery and noted the left atrial tumor to be attached near the intraatrial septum but more affixed on the left atrium just superior to an obvious PFO and has a relatively broad-base. The tumor including the pedicle was removed and the PFO was closed. Biopsy of the atrial tumor revealed myxoma (Fig. 3).

During her course, there was gradual resolution of numb- 

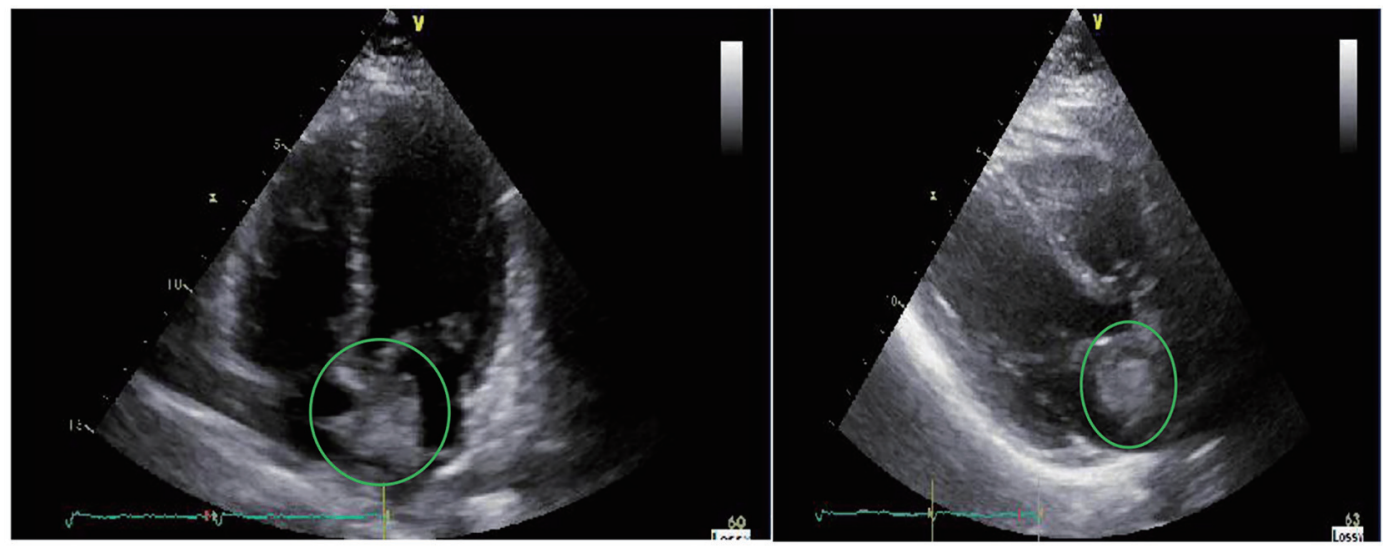

Figure 1. Transthoracic echocardiography revealing a heterogeneous mass measuring $37 \times 20 \mathrm{~mm}$ in the left atrium that is adherent to the interatrial septum.

ness of her left hand. No other neurologic complaints have been noted perioperatively. She was eventually discharged in stable condition. There was no recurrence of the initial symptoms or development of new neurologic deficits on regular ambulatory health maintenance evaluation. She did not complain of any difficulties in performing her activities of daily living including yoga to this date.

\section{Discussion}

Cerebrovascular ischemia is a consequence of inadequate perfusion and oxygenation to the brain to meet metabolic demand and is precipitated by a thromboemboli from central vessel or from the heart usually from the left cardiac chamber. Cardioembolic stroke from atrial myxoma and PFO has been elucidated and described in literature; however, the concurrent existence of both in a patient is very seldom. The coexistence of this congenital cardiac lesion and primary cardiac tumor might aggravate the occurrence and worsen the severity of an acute cerebrovascular event, thus, will require a different management strategy compared to the standard treatment modality.

Primary tumors of the heart are extremely rare [1] with an incidence of less than $0.1 \%$ [2], and in which myxomas are the most frequent in $70 \%$ of primary cardiac tumor in adults [3]. Left atrial myxoma accounts for $75-90 \%$ of the cardiac myxomas and occurs from 30 to 60 years of age [4] with women slightly vulnerable than men with male to female ratio of 1:2. Ninety percent of atrial myxomas are sporadic with unknown etiology [5] while $10 \%$ have been attributed to an autosomal dominant pattern known as Carney complex caused by PRKAR $1 \alpha$ gene mutation located on the long arm of chromosome 17 (region 17q22-24), characterized by multiple tumors, including atrial and extracardiac myxomas, non-myxomatous extracardiac tumors as well as cutaneous spotty pigmentation, schwannomas and various endocrine tumors $[6,7]$. Arterial embolism is the initial sign of left atrial myxoma, owing to a lack of cardiac manifestations in one-third of patients [8]. The atrial myxoma's polypoid and grape-like components can detach easily which is a nidus for tumor fragment embolization to the blood stream [9]. Aneurysm formation can occur which is triggered by endothelial thinning and reduced elasticity presumably effected by vascular wall growth of deposited embolic myxoma in infarcted arteries [10]. Neurologic complications are associated in $12 \%$ of patients with cardiac myxoma frequently presenting with cerebral infarction and in these pa-

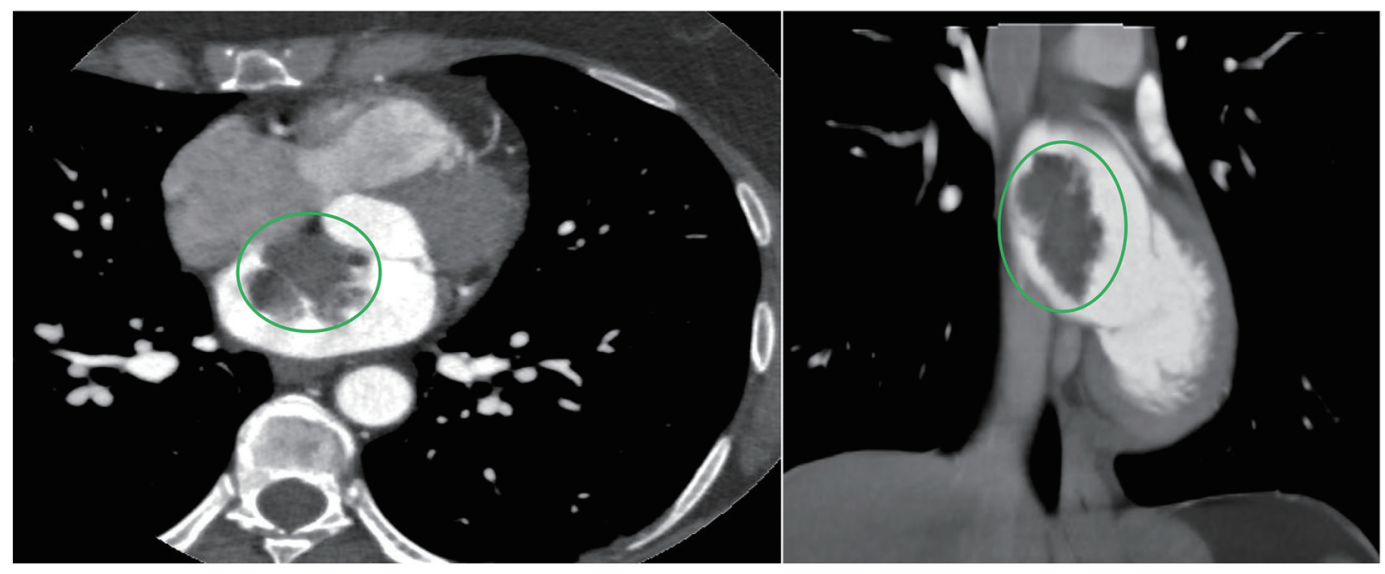

Figure 2. Cardiac computed tomography showing the mass in the left atrium that is likely attached to the interatrial septum. 


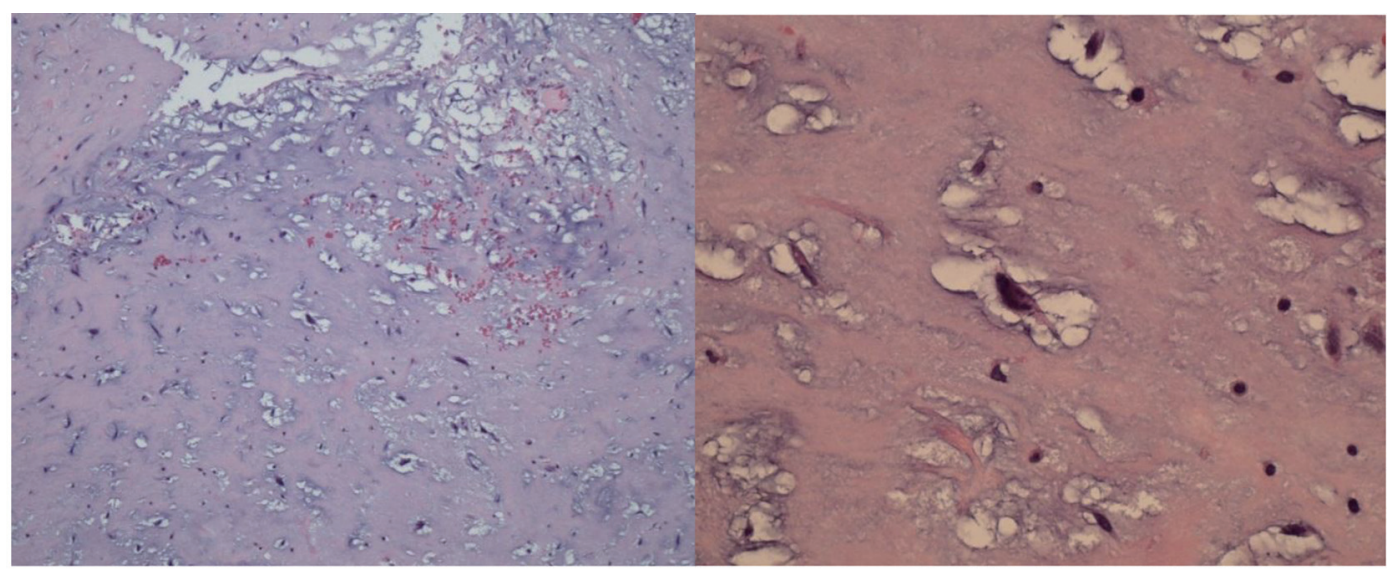

Figure 3. Histopathologic analysis of the resected atrial mass revealing myxomatous stroma with spindle-shaped mesenchymal cells.

tients, $22 \%$ had evidence of systemic myxomatous tumor embolization in addition to their neurologic manifestations [11].

PFO is a flap-like orifice between the atrial septa primum and secundum located at the fossa ovalis that remain after 1 year of age [12], and may linger frequently in adulthood. Its incidence is around $27 \%$ which has been evenly distributed by gender and age [13]. It has been recognized as a likely risk factor for a cerebrovascular event through paradoxical embolism, and has been occurring in more than $50 \%$ of young patients with cryptogenic stroke [14]; however, PFO solely is not correlated with an increased risk of recurrent stroke [15].

The available data were very scarce regarding the concomitant existence of left atrial myxoma and PFO in which either might have been the etiology of the cerebral ischemic event; however, it may also be an additive or synergistic effect to the evolution of the cerebrovascular event. Current literature unraveled a solitary case of combined myxoma, papillary fibroelastomas, and PFO as the inciting etiologies in a patient presenting with an ischemic stroke [16]. In our case, we considered that the cerebrovascular event was attributed from the left atrial myxoma and the concomitant PFO was an isolated incidental finding which was likely non-contributory to the event.

Atrial myxoma was evident on transthoracic echocardiogram but the PFO was not detected on our patient. The role of transesophageal echocardiogram intraoperatively may have detected the PFO which has been a common incidental diagnosis. The incidental finding of PFO intraoperatively dictated an additional surgical approach to manage such case though consensus on incidental PFO surgical closure has not been standardized.

There is no additional advantage in short-term perioperative results or in long-term longevity rates in patients with repaired or unrepaired incidental PFO [17]. Patients subjected to cardiothoracic surgery commonly have an incidental PFO but are not linked with increased perioperative complications; however, surgical closure likely unrelated to long-term survival and demonstrated a 2.47 times greater odds of postoperative stroke compared with those unrepaired [18]. There is no evidence to suggest that PFO closure is of any clinical benefit [19] and offers no greater advantage than medical therapy [20].

Evaluation for venous thromboembolism in young patients with cryptogenic stroke and PFO has been recommended by the current guidelines for stroke prevention by the American Heart Association (AHA)/American Stroke Association (ASA) in which anticoagulation has been advocated if it is confirmed [21]. On the other hand, the current guideline by the American College of Chest Physicians recommends antiplatelet therapy for patients with cryptogenic stroke who have a PFO irrespective of venous thromboembolism [22].

Expeditious resection is required once a possible diagnosis of myxoma has been conceived from imaging modalities because of the high embolization risk or sudden cardiac death [23]. Surgical resection outcome has been very satisfactory with a mortality rate of 2-6\% [23-25]. Myxoma recurrence risk occurs in $2-5 \%$ of cases $[26,27]$. Potential alternatives for the management of recurrent atrial myxoma include cardiac transplantation or autotransplantation [28, 29].

Our clinical vignette highlights a rare combination of left atrial myxoma and an incidental intraoperative finding of PFO, which either or in synergy could have been the culprit to the evolution of a cerebrovascular event.

\section{Conclusion}

Early recognition and evaluation of atrial myxoma and PFO in a patient presenting with a cerebrovascular event would initiate timely and appropriate intervention to halt the evolution of an impending stroke and eventual prevention of deleterious complications.

\section{Conflicts of Interest}

The authors declare that they have no conflicts of interest.

\section{Abbreviations}

PFO: patent foramen ovale; AHA: American Heart Association; ASA: American Stroke Association 


\section{References}

1. Reynen K. Frequency of primary tumors of the heart. Am J Cardiol. 1996;77(1):107.

2. Lam KY, Dickens P, Chan AC. Tumors of the heart. A 20year experience with a review of 12,485 consecutive autopsies. Arch Pathol Lab Med. 1993;117(10):1027-1031.

3. Vermeulen T, Conraads VM, Vrints C, Rodrigus IE. Recurrent left ventricular myxoma presenting as cerebrovascular accidents in a teenage girl. Acta Cardiol. 2009;64(6):811-814.

4. Reynen K. Cardiac myxomas. N Engl J Med. 1995;333(24):1610-1617.

5. McCarthy PM, Piehler JM, Schaff HV, Pluth JR, Orszulak TA, Vidaillet HJ, Jr., Carney JA. The significance of multiple, recurrent, and "complex" cardiac myxomas. J Thorac Cardiovasc Surg. 1986;91(3):389-396.

6. Kirschner LS, Carney JA, Pack SD, Taymans SE, Giatzakis C, Cho YS, Cho-Chung YS, et al. Mutations of the gene encoding the protein kinase A type I-alpha regulatory subunit in patients with the Carney complex. Nat Genet. 2000;26(1):89-92.

7. O'Rourke F, Dean N, Mouradian MS, Akhtar N, Shuaib A. Atrial myxoma as a cause of stroke: case report and discussion. CMAJ. 2003;169(10):1049-1051.

8. Nussbaum ES, Madison MT, Goddard JK, Lassig JP, Nussbaum LA. Peripheral intracranial aneurysms: management challenges in 60 consecutive cases. J Neurosurg. 2009;110(1):7-13.

9. Sha D, Fan G, Zhang J. Multiple cerebral infarction as the initial manifestation of left atrial myxoma: a case report and literature review. Acta Cardiol. 2014;69(2):189-192.

10. Li Q, Shang H, Zhou D, Liu R, He L, Zheng H. Repeated embolism and multiple aneurysms: central nervous system manifestations of cardiac myxoma. Eur J Neurol. 2008;15(12):e112-113.

11. Lee VH, Connolly HM, Brown RD, Jr. Central nervous system manifestations of cardiac myxoma. Arch Neurol. 2007;64(8):1115-1120.

12. Shah SN. Patent Foramen Ovale. http://emedicine.medscape.com/article/156863-overview/. Accessed December 4, 2016.

13. Hagen PT, Scholz DG, Edwards WD. Incidence and size of patent foramen ovale during the first 10 decades of life: an autopsy study of 965 normal hearts. Mayo Clin Proc. 1984;59(1):17-20.

14. Kizer JR, Devereux RB. Clinical practice. Patent foramen ovale in young adults with unexplained stroke. N Engl J Med. 2005;353(22):2361-2372.

15. Hara H, Schwartz RS. Patent foramen ovale. UpToDate, Waltham, MA. (Accessed on December 4, 2016.).

16. Roque J, Silva F, Arruda Pereira R, Cravino J. Multiple causes for an ischemic stroke: myxoma, papillary fibroelastomas and patent foramen ovale. HSR Proc Intensive Care Cardiovasc Anesth. 2012;4(3):187-191.
17. Truong QA, Garrido-Castro AC, Cannon CP. Patent foramen ovale. Incidental patent foramen ovale during cardiothoracic surgery: to repair or not to repair? Rev Cardiovasc Med. 2010;11(1):53-56.

18. Krasuski RA, Hart SA, Allen D, Qureshi A, Pettersson G, Houghtaling PL, Batizy LH, et al. Prevalence and repair of intraoperatively diagnosed patent foramen ovale and association with perioperative outcomes and long-term survival. JAMA. 2009;302(3):290-297.

19. Lo TT, Jarral OA, Shipolini AR, McCormack DJ. Should a patent foramen ovale found incidentally during isolated coronary surgery be closed? Interact Cardiovasc Thorac Surg. 2011;12(5):794-798.

20. Dalen JE, Alpert JS. Cryptogenic Strokes and Patent Foramen Ovales: What's the Right Treatment? Am J Med. 2016;129(11):1159-1162.

21. Kernan WN, Ovbiagele B, Black HR, Bravata DM, Chimowitz MI, Ezekowitz MD, Fang MC, et al. Guidelines for the prevention of stroke in patients with stroke and transient ischemic attack: a guideline for healthcare professionals from the American Heart Association/American Stroke Association. Stroke. 2014;45(7):2160-2236.

22. Lansberg MG, O'Donnell MJ, Khatri P, Lang ES, Nguyen-Huynh MN, Schwartz NE, Sonnenberg FA, et al. Antithrombotic and thrombolytic therapy for ischemic stroke: Antithrombotic Therapy and Prevention of Thrombosis, 9th ed: American College of Chest Physicians EvidenceBased Clinical Practice Guidelines. Chest. 2012;141(2 Suppl):e601S-636S.

23. Keeling IM, Oberwalder P, Anelli-Monti M, Schuchlenz H, Demel U, Tilz GP, Rehak P, et al. Cardiac myxomas: 24 years of experience in 49 patients. Eur J Cardiothorac Surg. 2002;22(6):971-977.

24. Bakaeen FG, Reardon MJ, Coselli JS, Miller CC, Howell JF, Lawrie GM, Espada R, et al. Surgical outcome in 85 patients with primary cardiac tumors. Am J Surg. 2003;186(6):641-647; discussion 647.

25. Centofanti P, Di Rosa E, Deorsola L, Dato GM, Patane F, La Torre M, Barbato L, et al. Primary cardiac tumors: early and late results of surgical treatment in 91 patients. Ann Thorac Surg. 1999;68(4):1236-1241.

26. D'Alfonso A, Catania S, Pierri MD, Matteucci SL, Rescigno G, Munch C, Staine J, et al. Atrial myxoma: a 25-year single-institutional follow-up study. J Cardiovasc Med (Hagerstown). 2008;9(2):178-181.

27. Pinede L, Duhaut P, Loire R. Clinical presentation of left atrial cardiac myxoma. A series of 112 consecutive cases. Medicine (Baltimore). 2001;80(3):159-172.

28. Goldstein DJ, Oz MC, Michler RE. Radical excisional therapy and total cardiac transplantation for recurrent atrial myxoma. Ann Thorac Surg. 1995;60(4):1105-1107.

29. Gammie JS, Abrishamchian AR, Griffith BP. Cardiac autotransplantation and radical bi-atrial resection for recurrent atrial myxoma. Ann Thorac Surg. 2007;83(4):15451547. 